\title{
GAMES REAL ACTORS COULD PLAY: THE CHALLENGE OF COMPLEXITY*
}

\author{
Fritz W. Scharpf
}

\begin{abstract}
This paper continues the examination of the validity of game-theoretic explanations in empirical social science and policy research. Assuming that real actors with bounded rationality would be unable to cope with the explosive complexity of $n$-person games, discussion focuses on the conditions under which corporate actors and coalitions, as well as collective and even aggregate actors, may be legitimately treated as unitary players. In addition, the importance of functional differentiation and ingroup-outgroup segmentation for the segregation of game-like interactions is explored.
\end{abstract}

KEY WORDS $\bullet$ composite actors $\bullet$ corporate actors $\bullet$ distrust $\bullet$ functional differentiation $\bullet$ game theory

\section{Introduction}

This is the second of three articles exploring the question of whether, and under which conditions, game-theoretical explanations may be applicable in empirical social-science and policy research. The question is worth asking since mathematical game theory, when interpreted as a reconstruction of strategically interdependent choices of rational actors, seems to impute cognitive and computational capacities to its idealized 'players' that are quite unrealistic when compared to the information and bounded-rationality constraints affecting real-world decision-makers. While the first article (Scharpf, 1990) discussed justifications for assuming that actors may in fact have complete information on each others' payoffs and strategy choices, the present paper focuses on the challenges arising from the potentially overwhelming complexity of real-world interdependent choices.

By itself, game-theoretic modelling does nothing to reduce real-world complexity. Nevertheless, I try to show that analysts may legitimately avail themselves of a range of radically simplifying forms of representation that help real-world actors to keep the cognitive complexity of interactions within manageable bounds. The present article explores justifications for the prevailing practice of treating several or many actors as a single 'player' and of restricting the analytical focus to subsets of interactions within wider sets of interdependent choices. Its purpose is to show that the conditions under

* Helpful comments by Arthur Benz, Renate Mayntz, Elinor Ostrom, Andreas Ryll, Uwe Schimank, Volker Schneider and George Tsebelis are gratefully acknowledged. 
which game-theoretical explanations may be usefully employed are approximated in a wider range of real-world constellations than one might expect in view of the seeming unrealism of the underlying assumptions.

The complexity of a game constellation may not deter mathematical game theorists, but the problem is of obvious importance for empirical researchers. To find the solution of a game played among $N$ players, each of whom must choose among $S$ strategies, actors as well as analysts are required to identify $S^{N} n$-tuples of strategies and to compare their outcomes. With only five players having to choose among three strategies each, that would already require comparison among $3^{5}=243$ different outcomes. Given the fact that the solutions of rational-analytic ${ }^{1}$ game theory are premised on the assumption that every player should anticipate the rational responses of all other players to the rationally expected moves of each of them, it is clear that the exploding complexity of simultaneous optimization would quickly overtax the computational capabilities of human minds operating with working memories that are narrowly constrained by the 'magical number seven, plus or minus two' (Miller, 1956). ${ }^{2}$

Moreover, the substantive contribution of game theory to our understanding of specific interaction constellations is largely concentrated on a very small number of 'archetypical' symmetrical $2 \times 2$ games - such as the ubiquitous Prisoner's Dilemma, Chicken, Assurance and Battle of the Sexes. These are members of a limited class of 78 strictly ordinal and strategically distinct $2 \times 2$ games whose characteristics have been reasonably well understood for some time (Rapoport and Guyer, 1966), while the much larger general class of $2 \times 2$ games has only recently been subjected to analyses of their strategic implications (Fraser and Kilgour, 1986; Kilgour and Fraser, 1988; Fishburn and Kilgour, 1990). Beyond that, we have analyses of highly structured choices in 'sophisticated voting games' (Farquharson, 1969;

1. Discussion will be limited to 'rational-analytic' applications of game theory that derive equilibrium outcomes from a reconstruction of intendedly rational ex-ante choices. Evolutionary and game-learning theories (Macy, 1989) modelling the retention, rather than the choice, of specific outcomes will not be considered here. In the social field, they have considerable explanatory power - but only for repetitive choices under relatively stable environmental conditions.

2. Miller's experimental findings seem to have held up over time, and it is now generally accepted that his 'magical number' does in fact constrain the number of distinct 'chunks' of information that can be simultaneously processed within the short-term working memory of the human mind. It should be understood, however, that these chunks may contain quite different amounts of aggregated information (Fischer, 1989; Johnstone and El-Bana, 1989; Turner and Engle, 1989). Thus, human capacity for information-processing is significantly extended as available primitive bits of information are 'compiled' into more encompassing and abstract concepts (Anderson, 1982). 
McKelvey and Niemi, 1978) in which all members of a (potentially large) group of actors are constrained to choose from the same set of (preferably binary) strategies, and in which outcomes are determined by the simple aggregation of votes. Similar simplifications facilitate game-theoretic solutions of 'compound games' which are constituted by pairwise interactions among large numbers of players, all of whom are playing the same symmetrical $2 \times 2$ game against each other (Colman, 1982; 156-66). For the general case of $n$-person games, however, requiring simultaneous optimization $^{3}$ among several or many players with different sets of strategies and different payoffs, mathematical game theory offers no computational procedures that would enable actors or researchers to cope with the problem of exploding complexity (Colman, 1982: 145). Thus, if real actors should in fact deal with interdependent choice situations according to the prescriptions of mathematical game theory, it seems that the games they could play must be narrowly circumscribed indeed.

For all we know, however, the modern world is characterized by two trends that combine to increase the degree of complexity with which actors in general, and policy-makers in particular, must cope. On the one hand, perceived interdependence among ecological, economic, cultural and political choices in the 'global village' (or on 'spaceship earth') seems to be rising rapidly while, on the other hand, the efficiency or even effectiveness of large, hierarchically integrated public and private-sector organizations seems to decline or fall apart before our eyes. Yet decentralization and fragmentation do not imply independence. In the public sector they go hand-in-hand with the rising importance of intergovernmental and neo-corporatist networks in policy-making and policy implementation, while in the private sector the establishment of profit centers and the hiving-off of independent firms by large corporations are associated with the rise of subcontracting, just-in-time production, joint ventures and world-wide cooperation in research and development - practices, that is, which enormously increase the operational interdependence among formally separate units.

In short, we seem to live in a world in which both the number of separate

3. There is, however, a line of game-theoretical work that greatly reduces cognitive requirements by replacing the assumption of simultaneous optimization with a sequential approach. Starting from an (historically given) status quo outcome, players are merely assumed to seek improvements of their respective positions through sequences of (actual or anticipated) moves and countermoves. The process will come to rest when an equilibrium outcome is reached. Theoretically, this work is unorthodox, and largely ignored by mainstream mathematical game theory, since it complements the Nash equilibrium concept with various more inclusive definitions [all derived from Nigel Howard's (1971) 'metagame analysis'] of 'nonmyopic' (Brams and Wittman, 1981) 'limited-move' (Zagare, 1984) or 'general meta-rational' (Fang et al., 1989) equilibria. While some of these solutions are only defined for $2 \times 2$ games, a subset has been shown to apply to $n$-person game constellations as well (Fraser and Hipel, 1984: $228-31,263-71$ ). 
action units and the degree of interdependence among their choices are simultaneously increasing. Thus it seems inevitable that game-theoretical models that would accurately represent the true complexity of existing networks of interdependent choices must far exceed the cognitive capabilities of boundedly rational actors (and empirical researchers as well). Yet when they are applicable, game-theoretical equilibrium solutions are unmatched in their power to explain the stable outcomes of interdependent choice situations. Thus, before we abandon a potentially most useful instrument of empirical social-science and policy research, it seems worthwhile to explore the conditions under which the focus of game-theoretical analyses might be legitimately narrowed.

To begin, we might well remind ourselves that, in the real world, interdependence is still not everywhere (Aldrich, 1979: 75-6) and, even more important, that not all instances of real interdependence are of the kind requiring game-like interactions. Thus, vast numbers of interdependent choices of producers and consumers in world-wide economic transactions are in fact coordinated through market mechanisms that will aggregate interaction effects into prices that all buyers and sellers can treat as parameters which are unaffected by their own choices. As a consequence, multiactor constellations that otherwise would have been immensely complex $n$-person games, are transformed into very simple games against nature.

Furthermore, for situations where market coordination is unavailable, James D. Thompson (1967:54-5) has introduced the useful distinction between 'pooled', 'sequential' and 'reciprocal' interdependence, each associated with specifically appropriate coordinating mechanisms. Thus, 'coordination by standardization' is said to be the adequate solution for pooled interdependence, while 'coordination by plan' is best suited for sequential interdependence. It is only reciprocal interdependence which seems to require 'coordination by mutual adjustment' (Thompson, 1967: 56). For present purposes, what matters is that standardization and planning, while requiring intensive interaction during their formative phases, will drastically reduce the need for direct interaction once they are in place. Interdependent actors are then merely required to observe severally the standards defined by 'routines or rules' or the decision 'schedules' established by a plan. In both cases, the mental operations required of individual actors in the implementation of rules or plans appear to be cognitively much less demanding than the simultaneous optimization of choices in an $n$-person game involving the same number of actors. Hence it is only under conditions of reciprocal interdependence requiring mutual adjustment, when 'the outputs of each become inputs for the others' (Thompson, 1967: 55), that actors find themselves in the paradigmatic 'game' situation where each must try to anticipate others' choices in the knowledge that they will do so as well. ${ }^{4}$

4. Even in reciprocal-choice situations, actors will of course profit greatly from well-chosen 
Thus, in many of the situations where game-theoretical explanations might run into unmanageable complexity, they are in fact not needed. But even if much interdependence may not be reciprocal, many interactions that do in fact require mutual adjustment still seem to hang together in complex patterns. Just as decisions within organizations will often affect choices within families and vice versa, so interactions between union members and leaders have predictable consequences for collective bargaining between unions and employers as well as for 'corporatist' negotiations between unions and governments or central banks. These, in turn, may affect the electoral competition between governments and opposition parties (Scharpf, 1987), as well as the attempts to coordinate fiscal and monetary policy measures internationally (Putnam and Bayne, 1984). Similar connections may be construed for practically all instances of reciprocal interaction within and between business firms, interest associations, political parties, parliamentary committees, government departments or international organizations.

But it is also clear that not all of these linkages can be fully reflected in the choices of actors involved in the larger network. Shop-floor union activists will be unable to assess the implications of Big-Seven summits for their own choices, and central banks may be not very knowledgeable observers of intra-union politics. In most real-world interactions, in short, the populations defined by the criterion of reciprocal interdependence are likely to be larger than the sets of actors circumscribed by the criterion of mutual awareness, which are again more inclusive than the small-numbers constellations within which actors are able to anticipate each other's choices with any degree of confidence and precision. In other words, even if the empirical domain of game-theoretical explanations is restricted to instances of reciprocal interdependence, we are likely to encounter patterns of interdependent choices whose size and complexity are beyond the ability, of actors and researchers alike, to identify equilibrium solutions in large $n$-person games.

It is not surprising, therefore, that empirical and historical studies that have made use of game-theoretical explanations have generally avoided the problem by focusing narrowly on constellations involving only a very small number of actors with few strategy choices. In fact, they usually manage to get by with the simplest type of model - symmetrical $2 \times 2$ games such as the Prisoner's Dilemma or Chicken. In order to do so, however, they must implicitly or explicitly (e.g. Snyder and Diesing, 1977: 81-6) reduce the complexity of real-world interactions in one of two ways - by treating a plurality or even a multitude of separate actors as a single composite player, or by concentrating on a small segment of real-world interactions and ignoring the

rules that reduce uncertainty, and facilitate cooperative solutions, by eliminating ranges of mutually damaging options from the sets of strategies that each is allowed to consider, and must anticipate from the other (Schotter, 1981; Ostrom, 1989). 
larger network of interdependent choices within which these are embedded.

Both of these practices have been roundly condemned by game-theorists (e.g. Alt and Eichengreen, 1987). Apart from coalition formation, it is indeed true that game theory offers no general algorithm that would justify treating a plurality of independent actors as a single player; and it has always been clear that games change their character if the number of players increases, and that valid solutions cannot be found if some participating players are ignored simply in order to focus on the remaining two-person game (von Neumann and Morgenstern, 1944). But these theoretical objections merely suggest that valid justifications for the prevailing practice must be sought outside the confines of mathematical game theory as such. If they exist, they must be rooted in real-world cognitive practices and institutional arrangements (that game theory may then reconstruct) which permit boundedly rational actors to cope with the complexity of their interdependent choices. I begin with a discussion of the reasons that could justify treating composite actors as unitary players in game-theoretical explanations.

\section{The Construction of Unitary Players}

Even though individuals may experience considerable difficulty in managing their 'multiple selves' (Elster, 1979; Schelling, 1984; Wiesenthal, 1990), their partners and opponents will generally not hesitate to treat them as unitary actors in everyday encounters. That points to the significance of external attribution by the social environment: individuals are considered unified 'actors' not because they have an easy time in making up their multiple minds, but because they are held individually accountable across time for their actions..$^{5}$ In other words, consistent actors are socially constructed by the attribution of a stream of actions and of a set of interests concomitant with these actions. The same is even more clearly true of composite actors composed of several or a great many individuals who are treated as a unit with unitary interests in social interactions.

In game theory as well, the notion of a 'player' is no more than a convenient label attached to a range of alternative courses of action (and, in sequential games, a history of past choices) combined with a set of associated payoffs. Thus there seems to be no game-theoretic reason why this label

5. The point is also emphasized, in the context of neo-Parsonian systems theory, by Niklas Luhmann (1984: 229) who, after noting that most human action should be explained not psychologically but situationally (a proposition with which rational choice theorists would emphatically agree), goes on: 'Und trotzdem wird alltagsweltlich Handeln auf Individuen zugerechnet. Ein so stark unrealistisches Verhalten kann nur mit einem Bedarf für Reduktion von Komplexität erklärt werden.' That seems fair enough, but how much would complexity be reduced if expectations of purposeful and consistent individual action were routinely disappointed? 
could not be attached to individuals, groups, organizations, coalitions of organizations, nation-states or alliances of states - provided that it is meaningful to ascribe a set of payoffs and consistent choices to these composite units. If the notion of a composite player nevertheless appears problematic, the difficulty seems to arise not from the absence of peculiar qualities of personhood, but from the specific demands that game-theoretic solution concepts make on the quality of choices - which may or may not be met in the case of individual or composite actors.

Game-theoretic solution concepts all seem to rely on a basic notion of 'strategic rationality' (Harsanyi, 1977; Elster, 1983: 77) that presupposes not only an ability to anticipate the rational choices of other players, but also a capacity to choose among feasible outcomes by maximizing a unified utility function. While individual players are often simply assumed to meet these requirements, the conditions under which they are likely to be met must be explicitly specified for composite actors. The first requirement presupposes a capacity to integrate potentially diverse perceptions of choice situations (Eden et al., 1981), while the second one strains the capacity for internal conflict resolution. ${ }^{6}$ More specifically, it presupposes an ability to construct a unified payoff matrix that is reasonably stable over time, in the face of inherently diverse substantive interests, intertemporal interests and interpersonal interests held by individual members of the respective collectivity. Since it is impossible to maximize more than one value at the same time, it is also inevitable that some of these competing priorities - of one kind over another, of one individual or group over another, or of short-term over longterm interests - will have to be consciously sacrificed in the choice of an optimal strategy. In that sense, strategic rationality could also be defined as the ability to accept, or to impose, these necessary sacrifices.?

Since different individuals are also likely to differ in their substantive concerns and in their time preferences, ${ }^{8}$ analyses of the strategic capability

6. The requirement of a capacity for conflict resolution is more basic than the search for a social-choice mechanism that would 'aggregate' individual preferences into a transitive collective preference order. That this goal cannot be attained generally without violating certain highly plausible normative requirements (Arrow, 1951; Sen, 1970; Miller and Moe, 1986) does not argue against the pragmatic superiority of some constitutional arrangements over others (Buchanan, 1954; Frey, 1990), and it certainly does not argue against the need for, and possible effectiveness of, conflict resolution in collective choice processes.

7. This definition of strategic rationality is broader than Elster's (1979: 4-18) 'generalized capacity for global maximization' - which perceives rationality in purely intertemporal terms, as a capability to relate to the future by pursuing 'indirect strategies' (e.g. by investing or by strategic waiting). It seems clear, however, that rationality is as much impaired by an inability to accept tradeoffs among several types of substantive interests (wanting to eat one's cake and have it) or interpersonal interests (trying to please everybody).

8. In addition, a perceived lack of individual control over future choices may shorten the time horizon of all participants in collective-decision processes (Brennan and Buchanan, 1985: 78). 
of composite actors may justifiably concentrate on the interpersonal dimension of the problem. Thus, in order to be treated as players with strategic rationality, composite actors must either achieve a high degree of cognitive and normative integration of their members' action orientations (Feld and Grofman, 1990), or they must have a capacity for consistently discriminating against certain perspectives and interests, and hence against certain members. Different types of composite actors will meet these preconditions to differing degrees. Moreover, as I try to show, it may be useful to model composite actors as unitary 'players' even if their strategic capability is limited or zero - but then the moves of such players cannot be directly derived from the construct of collective payoffs; they must be reconstructed (in models of two-level games) from the choices of their constituent members.

\section{Corporate Actors}

Corporate actors (Coleman, 1974, 1981, 1990: chs 16-17, 20-1) are characterized by the legal attribution of collective rights, resources and duties combined with an internal capability for making collectively binding decisions and for committing collective resources. When these conditions are met, they will indeed appear as unit actors from the outside - in the same sense in which a yacht that is sailed by a multi-person crew will appear as a unit to its competitors in a race. Whether such unit actors are also capable of strategic rationality, in the sense defined above, is a separate question, the answer to which depends on the nature and effectiveness of their internal decision rules and on the interaction orientations prevailing among their members (Scharpf, 1989).

If internal rules permit effective choices by majority or hierarchical decision, strategic rationality in the face of internal dissensus may be achieved through consistent discrimination - by decisions favoring some member interests and ignoring others. If the (de facto) decision rule should be unanimity, however, discrimination among insiders is impossible (Buchanan and Tullock, 1962). When that is so, the capacity for strategic action depends entirely on the second condition. If all members are willing and able to define their own choice criteria within a solidaristic interaction orientation ${ }^{9}$ or, what amounts to the same thing, in terms relating to the common interest of the group or organization as a whole (Coleman, 1990: 383-7; Feld and Grofman, 1990), even corporate actors operating under the unanimity rule may be able to arrive at strategically rational choices.

9. While solidaristic transformations of the 'effective matrix' (Kelley and Thibaut, 1978) are easily identified in experimental game research (Liebrand and van Rung, 1985; McClintock and Liebrand, 1988), there is little systematic knowledge about the preconditions of such transformations in real-world choice situations. 
But the stipulated conditions often will not be met in practice. Even organizations whose formal rules seem to provide for hierarchical control or for majority decisions often must operate under de facto unanimity rules, and solidaristic orientations are hard to achieve and even harder to maintain. Sometimes, under such circumstances, the corporate actor will disintegrate into smaller units, each of which can then be treated as a separate player capable of strategic rationality in game-theoretical analyses. More often, however, the corporate actor will retain its collective identity and accountability as well as its capacity for collectively binding decisions - but with de facto decision rules approaching unanimity, and with members or groups of members maximizing their separate, rather than their joint, interests. Such conditions have been analyzed in my article on the 'joint-decision trap' in German federalism and in the European Community (Scharpf, 1988). But while the focus there had been on the internal bargaining games among members, the present perspective demands a view from the outside.

In games with external opponents, a corporate actor in the joint-decision trap may still be represented as a single player having to choose a single move within a well-defined set of options. Its choice, however, is not derived from a unified utility function and a single cognitive map; instead it is the resultant of the self-interested choices of its constituent members - individuals, organizational subunits or coalitions of these. Thus, the corporate actor's own capacity for strategic action in the external game is constrained, and its actual choices, when considered in isolation, would not conform to standard game-theoretical solution concepts. But these choices can nevertheless be analyzed as the outcome of a second-level game between the corporate actor and its constituent members (Putnam, 1988). ${ }^{10}$ If members are purely selfinterested, each of them will separately evaluate the expected outcomes of collective choices in the light of their own costs and benefits. Under such conditions, unanimous agreement is possible only for corporate strategies whose expected outcomes (including side payments) are superior to the outcome associated with non-agreement - often the status quo - for all of the individuals or groups whose agreement is necessary. As a consequence, the external choices of the corporate actor will be characterized by a high degree of inertia, and they will be highly predictable to anybody who is familiar with the internal division of interest.

The implications of such constellations for the external game are ambiguous. On the one hand, corporate actors with high internal consensus requirements will find it difficult to exploit new opportunities that are attractive on balance, but not for each member individually, and they will encounter similar difficulties when it would be rational to cut their losses in response to worsening conditions. That is clearly a disadvantage in games

10. This, essentially, is also the solution which psychoanalysis has found for conceptualizing the multiple selfs of individuals (Turkle, 1988). 
against nature as well as in zero-sum games against opponents with greater strategic capability. On the other hand, their very lack of strategic rationality will also make them resist compromises and appeals to common interest in cooperative positive-sum games unless these should be unequivocally attractive for all their members. Thus, corporate actors caught in the jointdecision trap may drive a harder bargain in game constellations resembling Battle of the Sexes or the Chicken game (Schelling, 1960), when their known inability to make strategic concessions may force their partners to act on the maxim 'der Klügere gibt nach' - assuming that they cannot avoid dealing with such an unattractive opponent altogether.

\section{Coalitions}

Phenomenologically, the case of corporate actors with internal factions and veto groups shades over into ad hoc or longer lasting coalitions among independent actors joining forces for certain purposes. With regard to the complexity problem discussed in this article, coalitions also seem to have the invaluable advantage of drastically reducing the number of effective players, in the extreme case transforming a large $n$-person game into a mere twoperson game played between a majority coalition and the minority. Moreover, coalitions are extensively treated in the game-theoretical literature. Indeed, it seems that whenever agreements are assumed to be feasible in an $n$-person constellation, the game-theoretical interest shifts entirely to problems of coalition formation. The basic analytical instrument is the characteristic function of a game, identifying the subsets of players who, by coordinating their choices, can do better for themselves than they could do by playing independently. The goal is to determine which coalitions are likely to be formed, and how the payoff obtained by a coalition will be distributed among its members (Rapoport, 1970: 67; Kahan and Rapoport, 1984).

Unfortunately, however, this line of work will not contribute much to our present concern with managing the exploding complexity of $n$-person games. In trying to determine which coalitions could profitably be formed, analysts must first find the solution to the original $n$-person game to identify the payoffs that each player could obtain independently, and they then need to work through the outcomes associated with opportunities for coordination among all possible subsets of players. When considered as a tool for empirical research, these are surely unrealistic propositions. Thus it is no wonder that practically all analytical treatments of coalition problems deal with extremely simple types of $n$-person games, such as voting games or 'compound games', in which strategies and payoffs are standardized and easily aggregated."

11. See Riker and Ordeshook (1973), Ordeshook (1986) and the literature cited in note 3 above. Even within these limitations, theoretically derived conclusions about which coalitions 
What seems to be lacking in the mainstream of game-theoretic analyses is an explicit conceptualization of the two-level character of the games involved. Coalitions may not be able to pursue goals that are independent from the interests of their individual members - but they are certainly confronted with sets of strategy options that are distinct from those among which their individual members, acting separately, could reasonably have chosen. That is obviously so when the coalition creates a common agency that would not otherwise have existed, but it is also true when the coalition can only act through its members. In the absence of NATO, stationing troops in Germany would not have been a meaningful option for Canada and even though the strategy space available to NATO is obviously limited by the resources made available by its members, it does not make analytical sense to try to reconstruct NATO options through the combinatorics of strategies that individual countries might reasonably consider when acting alone.

When the composite-actor character of coalitions is explicitly recognized, there must also be a dramatic reduction in the analytical complexity of $n$-person games. As in the case of corporate actors, it is possible, on the first level, to explore the strategy space of the coalition (which is constrained by the resources contributed by members) in relation to the aggregate strategy options of the opposition. Assuming that the coalition is not maximizing a unified utility function, it is then necessary, on the second level, to explore the impact of first-level outcomes on the payoffs (costs and benefits) of each member of the coalition. This is the logic of two-level games that was explicated in recent studies of French coalition politics (Tsebelis, 1988, 1990: $\mathrm{ch}$. 7) and of the interaction between party politics and coalitiongovernment politics in parliamentary system (Laver and Shepsle, 1990). It can be extended, I suggest, to all types of coalitions, even if they cannot be reduced to the relatively simple form of voting games.

Equally important, for present purposes, are the processes and criteria by which coalitions define and select their collective strategies. While these will vary empirically, coalitions will generally differ from corporate actors by the fact that their existence, or at least their identity, is more affected by the exit of individual members. Thus it seems plausible to assume that all coalitions, while they last, must reach their decisions by unanimous agreement. If it is further assumed that members will join a coalition in order to maximize their individual self-interest (rather than solidaristically defined common interests), conditions will correspond to the joint-decision trap discussed above - except that the exit option may be more readily available.

(e.g. 'minimum winning coalitions') ought to be formed, and how the total payoffs obtained by a coalition ought to be distributed among its members (e.g. according to 'Shapley values'), are neither easily reproduced under experimental conditions (Selten and Schuster, 1970) nor confirmed by empirical research on parliamentary coalitions (Nolte, 1988). 
But this is a difference that is likely to make a difference: When the cost of exit is low, the pressure to reach an agreement, as well as the benefits that might be obtained by 'holding out' (Buchanan and Tullock, 1962: chs 7-8) are low as well. Thus, collective goods implying unequal costs and benefits are less likely to be obtained, but agreements actually reached are more likely to reflect the current preferences of all members than is true in corporate actors where exit is costly, and where the 'default condition' in case of nonagreement (Ostrom, 1986) is likely to favor the status quo of past agreements that may no longer represent present interests (Scharpf, 1988).

\section{Collective Actors}

Corporate actors with a capacity for making collectively binding decisions, and coalitions based on binding agreements, are not the only type of composite actor that may legitimately be treated as unitary players in game-theoretical explanations. Under conditions which approximate purecoordination games, purposeful collective action may be achieved even in the absence of formal organization, explicit agreement or even informal leadership, not only in team-like, face-to-face groups or in mass demonstrations and uprisings where everybody is able to observe everybody else, but even within large and geographically dispersed social movements. But tacit self-coordination among large numbers of individuals presupposes a highly salient shared interest or action motive that all members of the movement may impute to each other, and it depends on highly visible and unambiguous characteristics of the situation to which the response of other members may be safely predicted. When these conditions were in fact present, the American civil-rights movement, the anti-nuclear protest and peace movements in Western Europe, or the democratic protest movements in Eastern Europe were effective collective actors indeed. Yet when the ordinary ambiguity of situations prevails again, social movements must either transform themselves into corporate actors (such as organized interest groups or political parties) or they are likely to disintegrate into a plurality of divergent groups, or dissolve altogether (Offe, 1988, 1989).

Even under the best of circumstances, however, the strategic capability of self-coordinated collective actors remains limited. Though their members may share solidaristic orientations, and may even be willing to accept considerable sacrifice in the pursuit of their collective goals, their dependence on tacit coordination and spontaneous individual action practically precludes the possibility of long-term or indirect strategies, or of strategic selfrestraint to consolidate limited gains or to avoid overshooting (Elster, 1979). Moreover, being constrained to use coordination strategies that must be 'obvious' for all members (Schelling, 1960), their actions are also easily anticipated by others. Thus, if they do not succeed quickly by direct mass action, they will often be outmaneuvered by organized opponents with lesser 
numbers and resources but a greater capacity for dissimulation, strategic waiting and indirect strategies. ${ }^{12}$ Nevertheless, if due allowance is made for the limits of their strategic capabilities (and hence for the resulting asymmetries in games played against opponents with greater strategic rationality), there is no reason why collective actors should not be modelled as single players in game-theoretical explanations.

\section{Aggregate Actors $^{13}$}

At an even lower level of strategic capability, the same may also be true of mere aggregates of actors consisting of similarly situated individuals that do not even attempt to coordinate their separate actions. Still, if their interests and situational constraints are similar, it will make sense for others to anticipate their aggregate responses to a given stimulus as if they were a single composite actor. The resulting game will, of course, be highly asymmetrical - but it is still different from a game against nature, since the individual members of the aggregate actor will not only respond to, but are able to anticipate, the moves of other players who are capable of strategic action. ${ }^{14}$

As George Tsebelis (1989) has argued, the proper way to model interactions between aggregate actors and corporate actors of comparable magnitude is as a sequential game in which the aggregate actor must move second, responding to available information about the first move of the strategic actor (who should be modelled as a 'Stackelberg leader'). ${ }^{15}$ The reason seems straightforward: If the aggregate player is constituted by a large number of uncoordinated actors, all of these must calculate their own choices individually without being able to count on their aggregate power. Thus, since each of them could not individually influence the choices of the strategic opponent, none of them will have reason to try making a preemptive first move.

12. A textbook example is provided by the rise and fall of the Paris Commune (Haffner, 1987).

13. This category includes phenomena that are usually discussed in the literature under the label of 'collective behavior' (e.g. Coleman, 1990: ch. 9). The focus there is usually on the internal dynamics within crowds, while the emphasis here is on the 'external game' between the crowd and actors that are capable of strategic rationality.

14. In economics, Rational Expectations theorists claim that firms, workers and households will anticipate the stimuli of countercyclical demand management. The implication is that game-theoretic models, rather than the response functions of conventional macroeconomic models, should be used to analyze the interactions between economic policy-makers and their target populations.

15. The implications of leadership and followership were first analyzed in the context of oligopolistic markets (Stackelberg, 1934). They have since been generalized to characterize a specific 'Stackelberg equilibrium' in sequential games (Rasmussen, 1989: 79-80; Fang et al., 1989). 
It should be noted, however, that Stackelberg followership is not necessarily a disadvantage. As Tsebelis has further shown, moving first is clearly advantageous only in games with more than one Nash equilibrium (e.g. in Chicken and Battle of the Sexes), none of which is jointly preferred by both players (as would be true in the Assurance game). In games with a single equilibrium, the sequence of moves does not matter, while moving last is preferable in games that have no equilibrium in pure strategies. Thus, there are again certain game constellations in which composite actors, who as such are incapable of strategic rationality, will do well playing against corporate actors with fully developed rational capabilities. ${ }^{16}$

Moreover, under certain conditions not considered by Tsebelis, aggregate actors may also be able to make the first move in interactions with corporate actors. That may be so when their members are responding to external events that could be construed as a move of 'nature', ${ }^{17}$ or of human actors outside of the game presently considered. ${ }^{18}$ Even more interesting from a theoretical point of view are 'autodynamic processes' (Mayntz and Nedelmann, 1987; Coleman, 1990: ch. 9) in which first-move capabilities are endogenously generated by the individual members of a population who are responding to each other's choices - without, however, attempting or achieving purposeful coordination.

Instances that seem amenable to a game-theoretical interpretation include interactions between currency speculation and national monetary policy or, even more dramatically, between mass emigration from the GDR and the unification policy of the West German government in the Winter and Spring of 1990. These events can be modelled as a sequential game in which escalating emigration forced the government, against its own better judgment, to propose an early currency union between West and East Germany. In the absence of purposeful coordination, this first-move capability of a - loosely circumscribed $^{19}$ - aggregate player was generated by individuals responding

16. This corresponds well with my earlier reconstruction of the nested economic policy coordination and election games played between unions, governments and electorates in the 1970s (Scharpf, 1987). As it was played by Keynesian governments, the game had no overall equilibrium solution. Thus even organizationally fragmented unions, lacking the capacity for strategic commitment, were able to exploit governments that were committed to maintain full employment. As played by Monetarist governments, however, the game had a single equilibrium outcome that could not be exploited by unions, regardless of their strategic capability.

17. Think of emigration in response to a famine.

18. Thus, the decision of the US Federal Reserve to raise dollar interest rates in 1980/81 had a massive impact on the investment behavior of European firms - which then could be construed as a first move by business (perceived as an aggregate actor) in the economic policy games of European countries.

19. While it was clear that not everybody could or would leave the GDR, there was no way in which the population that was 'threatening' to leave could have been precisely circumscribed - a fact which did not detract from the perception that governments were in fact playing a losing game against an identifiable opponent. 
to a deterioration of their present circumstances caused by the disappearance of fellow workers, teachers and doctors in the neighborhood, and to news about the rapid overcrowding of housing and job markets in West Germany.

In a two-level model, their relationship with one another might be represented as a simultaneous $n$-person 'Commons Dilemma' (Hardin and Baden, 1977) or as a sequential dilemma game with players responding to different 'thresholds' or facing different constraints (Granovetter, 1978; Granovetter and Soong, 1983; Coleman, 1990: chs 9 and 33). The overall pattern of interactions might then be modelled as an even more complex multi-level game involving also the West German electorate, the East German government, several foreign governments and diverse international organizations. ${ }^{20}$ What matters here, however, is the simpler point that interaction effects among the members of a population may indeed transform that population into an aggregate player with first-move capabilities in games played against external opponents.

To summarize: I have tried to show that the prevailing practice of treating a plurality of actors as a single player in game-theoretical applications is often fully justified. In the case of corporate actors relying on institutional arrangements that permit collectively binding decisions to be made, that is perhaps obvious - and the same may be true of actors who have joined together in a coalition. More interesting is the fact that 'collective actors' depending on tacit self-coordination, and even uncoordinated 'aggregate actors', may also be legitimately modelled as single players in gametheoretical analyses. What needs careful attention, however, are the ensuing asymmetries in strategic capabilities - i.e. in the ability of composite players to optimize their choices in the substantive, the intertemporal, and the interpersonal dimension. Nevertheless, a lack of strategic capability on the part of some or all players does not rule out game-theoretical analysis, and it does not even necessarily imply unfavorable outcomes in games played against more rational opponents.

\section{Boundaries Between Games}

While the first part of this article discussed various ways in which composite actors might legitimately be treated as unitary players in game-theoretical explanations, the focus is now shifted to the second simplifying strategy that is generally pursued in historical or empirical applications. It seeks to reduce the complexity of $n$-person games by focusing narrowly on some interactions among a few players, while ignoring other interactions in which the same players are also involved. Again, the game-theoretical legitimacy of such

20. But, as Werner Güth had reason to remark at a recent conference on Connected Games: 'Modelling is easy; solutions are the problem.' 
practices is doubtful. When connections do exist, they may be ignored only if the narrower segment selected can be isolated as a subgame whose equilibrium solution does not depend on the wider context of interactions (Ordeshook, 1986: 139-42) - a condition which usually is shown to be neither true nor a priori plausible. At the same time, however, it can be shown that game-like interactions are in fact dependent on mechanisms that, somehow, are able to segregate relatively small 'constituent games' from the wider networks of interactions in which they are embedded.

\section{The Need for Boundaries}

Within empirically oriented game research, these questions are addressed by an emerging literature on 'connected', 'linked', 'nested' or 'multi-level games'. ${ }^{21}$ Even though the emphasis there is generally on the discovery of connections among games that are conventionally treated as being separate, the implication is that these connections are, somehow, analytically distinguishable from, and cognitively more tractable than, the fusion of all constituent games into a single $n$-person game (Tsebelis, 1990: 55-7). While there is as yet no explicit agreement on what distinguishes constituent games from mere connections among such games, information asymmetries (and hence an element of surprise) seem to be significant in most treatments. An example is provided by Shepsle's (1985) discussion of 'interconnections' among games. In the illustration he uses, $A$ is simultaneously playing against $B$ and $C$; he is trying to maximize the sum of his payoffs from both games, and he is constrained to use the same strategy in both games. What is critical is the further assumption that neither $B$ nor $C$ should be aware of the fact that $A$ is playing against anyone else, so that $A$ 's choice of an optimal strategy may surprise one or both of them. However, if $B$ and $C$ had been aware of this connection, the linked game would have been transformed into an ordinary three-person game. In other words, what distinguishes connected games from $n$-person games in this example (and in many others) is incomplete information about the payoffs of at least one player on the part of some other players - who are furthermore assumed to be unaware of their own ignorance.

These are special assumptions that may bring to mind the caveat that 'by cleverly choosing the nature of uncertainty ... one may get out of gametheoretic analysis whatever one wishes' (Kreps and Wilson, 1982: 276). At any rate, the conditions specified are unlikely to be stable. Some of the players will be surprised by the outcome, and hence will have reason to change their expectations and their strategies. If they become fully aware of

21. The literature includes works by Denzau et al. (1985); Shepsle (1985); Alt et al. (1988); Laver and Shepsle (1990); Alt and Eichengreen (1987); Scharpf (1987); Putnam (1988); Milgrom et al. (1988); Greif et al. (1990); Tsebelis (1988, 1990). 
the games that are in fact being played, the interaction will become an $n$-person game with complete information. Of greater theoretical and practical interest, however, is the possibility that actors will become aware of the fact of their interconnectedness without becoming fully informed of each others' strategies and payoffs - and hence of the precise form of the game that the 'hinge player' is in fact playing. In other words, while information is still incomplete, the fact that a game of incomplete information is being played is common knowledge.

To explore the implications of such constellations, consider a thought experiment with an extended chain of Shepsle-type interactions in which each player is constrained to use a single strategy against both neighbors while trying to maximize the joint payoff from both games. Assume further that players are aware of the involvement of all other players, but that their knowledge of others' strategy options and payoffs, and hence their ability to anticipate others' strategy choices, extends only to their proximate neighbors.

$$
A \leftrightarrow B \leftrightarrow C \leftrightarrow D \leftrightarrow E \leftrightarrow F
$$

Take the case of player $C$, who will know that her neighbor $B$ is also involved in a game with $A$, and is trying to maximize the combined payoffs from both games. But since $C$ is unable to know $A$ 's true payoffs (which are known to $B$ ), she is also unable to estimate $B$ 's optimal response in the $B-A$ game, and hence she will not be able to anticipate $B$ 's optimal strategy against herself. The same is true if $C$ turns her attention to the game against $D$, which is similarly affected by her ignorance of $E$ 's payoffs. The situation would not change if the information constraint was relaxed so that $C$ would also know the payoffs of the $D-E$ game, but remained ignorant about the $E-F$ game. By a process of backward induction, ignorance of $E-F$ would invalidate her estimate of $D-E$, and hence of $D$ 's optimal strategy in $C-D$ as well. Thus, if information constraints apply anywhere in a network of connected games, uncertainty will spread throughout the network. ${ }^{22}$

In my previous paper I have argued that insuperable uncertainty about others' payoffs (and, hence, about their likely strategy choices) will persuade rational players to prepare for the worst by adopting cautious (maximin) strategies themselves (Scharpf, 1990: 475-7). The same assumption is made in discussions of the consequences of information asymmetries in the 'market for lemons' (Akerlof, 1970) or of the consequences of 'opportunism'

22. Under the assumptions introduced above, the backward induction of uncertainty would not affect players that have a single dominant strategy against both their immediate neighbors. While such players are 'uncertainty-proof' - in analogy to the concept of 'deception-proof games' introduced by Brams (1977) - their immediate neighbors would not profit much from having this information as long as they themselves could not anticipate the move of the player on their other side. 
in the transaction-cost literature (Williamson, 1975, 1985). For illustration, take the example of the Assurance game where players' interests objectively coincide. Here, the optimal outcome of mutual cooperation is only assured if both players are informed of each other's payoffs, if each of them is certain of the other's knowledge of these payoffs, and if each of them trusts the other's rationality. If there should be doubt about any one of these elements in either player's mind, 'defection' (assuring at least the maximin payoff) would become a rational choice (Raub and Keren, 1990; Holler and Host, 1990). Moreover, if both should proceed from the same skeptical assumptions, the outcome would be self-validating, since mutual defection is in fact a Nash equilibrium in the Assurance game. ${ }^{23}$

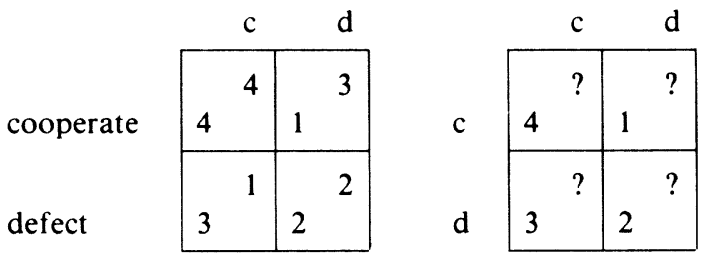

Figure 1. Assurance Game with Incomplete Information

Thus, if everybody should adopt maximin strategies, ${ }^{24}$ the outcomes will be suboptimal at least for some players who will be unable to take advantage of opportunities for cooperation or exploitation that might have arisen under complete-information conditions. ${ }^{25}$ In other words, potentially 'profitable' games will be played as if they were 'unprofitable' in the sense defined by Harsanyi (1977: 136-8). There is also no reason to think that generalized suspicion and caution cannot prevail in reality - they seem to have been approximated in 18th-century Naples (Pagden, 1988) for instance, or in East Germany until very recently, and they also seem to prevail in many big-city ghettos. Nevertheless, highly interdependent modern societies could not function as they do if pervasive distrust were a universal characteristic of interactions (Luhmann, 1988a). Thus our thought experiment encourages us to search for mechanisms that real-world actors could rely upon to increase their ability to predict each other's strategic choices.

23. The same would be true a fortiori when the cautious strategy is dominant, as is true in the Prisoner's Dilemma. In Chicken, a cautious player might be surprised by the opponent's cautious (and cooperative) move, and might be tempted to exploit it in the next round. But since the same idea might also occur to the opponent, caution would continue to be the better part of valor.

24. For a player involved in a chain of games as discussed above, the definition of a maximin strategy would, of course, relate to combinations of the strategy options of all immediate neighbors.

25. The problem does, of course, not arise in all games since uncertainty will not affect players that have a dominant strategy. 
A considerable degree of predictability is, of course, created by systems of rules, conventions and routines. They were mentioned above as instruments of 'standardization', facilitating coordination under conditions of 'pooled interdependence'. But rules, conventions and routines are also important in situations of 'reciprocal interdependence' and in game-like interactions. If their prescriptions are common knowledge, they will create conditions of mutual predictability among actors who otherwise could not rationally anticipate each other's choices (Nelson and Winter, 1982; Heiner, 1983). ${ }^{26}$

Nevertheless, standardized rules provide a solution only for standard situations. They will not accommodate idiosyncratic concerns, nor will they be adequate for new or highly variable situations. In many of the most important choice situations, therefore, they need to be complemented by more fine-grained information about others' payoffs and strategy options. In my earlier paper, I have tried to show how the possibility of highly specific and trustworthy communication may arise endogenously from the ongoing interactions among groups of actors benefiting from opportunities for mutual observation and sanctioning. The question now is how such communication may be protected against the uncertainty and distrust arising from the outside contacts in which the players of a 'constituent game' may also be involved. Again, answers may be sought outside the domain of game theory proper - in mechanisms of social differentiation that have the power of effectively segregating sets of otherwise interdependent interactions from each other.

\section{Boundaries of Distrust}

The first of these mechanisms can be derived from a variation of the thought experiment introduced above. If $B, C$ and $D$, instead of participating in chain-like interactions, formed a clique, each would have complete information about the payoffs of the other two. By itself, that would not yet change their predicament, since $C$ and $D$ would still remain ignorant of $A$ 's payoffs which, however, are known to $B$. From their point of view, therefore, $B$ would remain as unpredictable as before.

26. When the underlying problem has the structure of a 'game of pure coordination', standardization may be achieved through the unplanned evolution of 'conventions' (Schotter, 1981). By contrast, in 'social dilemma' situations, the emergence of norms is either dependent on ongoing interactions within small groups (Kliemt and Schauenberg, 1984; Coleman, 1986) or will require purposeful collective action (Brennan and Buchanan, 1985; Ostrom, 1989, 1990; Weissing and Ostrom, 1990). 


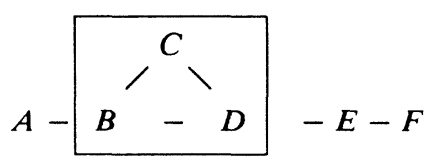

Figure 2. Unpredictability within Cliques

The situation would, of course, be different if $B, C$ and $D$ were able to form a completely isolated clique - within which profitable complete-information games could then be played. But even in the presence of outside connections, the backward induction of uncertainty could be avoided if the members of the clique would adopt a rule according to which all outsiders should be treated as being untrustworthy (or should be assumed to hold competitive or hostile interaction orientations). As a consequence, external interactions would be transformed into either games with incomplete information or zero-sum games. In both cases, 'linking-pin' players would have to derive their strategy choices in these external games entirely from an examination of their own payoffs. Since these are known to all other members of the ingroup, the predictability of interactions among ingroup members would no longer be destroyed by outside contacts. Trust among insiders, in other words, could arise from common distrust of outsiders. More important for present purposes, interactions in the 'constituent game' would be qualitatively different from interactions 'connecting' such games - preventing the overall pattern of interactions from degenerating into a large $n$-person game of unmanageable complexity.

The resulting pattern would resemble the 'amoral familism' which Edward Banfield (1958) had found in his study of backward villages in the south of Italy where trust and cooperation within the family coexisted with complete distrust and morally unrestrained cheating among individuals not belonging to the same family. Another, more modern example is provided by the norms of solidarity within, and ritualistic hostility between, partisan factions that Renate Mayntz and Friedhelm Neidhardt (1989) had found in the political culture of the West German parliament. ${ }^{27}$ More generally, ingroup-outgroup boundaries seem to structure large areas of social interaction in which hostility, or a competitive orientation, toward outsiders helps to maintain trustworthiness, and perhaps solidarity, among insiders. Examples include not only organized crime or instances of intense religious, ethnic or international conflict, but much of competitive politics,

27. The findings fit perfectly with Carl Schmitt's (1932) famous definition of politics as a 'friend-foe relationship'. 
competitive sports and competitive business - including the 'clan'-like combinations of Japanese firms that are said to be internally solidaristic while engaged in fierce competition with each other (Ouchi, 1984; Deutschmann, 1989).

However, if ingroup-outgroup differentiation were the general organizing principle, societies would be segmented into non-overlapping clusters of actors within which trustworthy interaction is possible, while all contacts between such groups would be characterized by distrust and generalized caution. Yet modern Western societies could not function as they $\mathrm{do}^{28}$ if competitors in business could not also cooperate in the same political party; if members of different political camps could not trust each other's research findings; or if adherents of different religions could not play together on the same soccer team. In short, while ingroup-outgroup segmentation facilitates trust, it does so by creating boundaries of distrust whose social cost must be considerable under conditions of high interdependence in modern societies. Thus, we must assume that there will be additional, and less damaging, mechanisms that are able to shield trustworthy communication in completeinformation games from interference by the multitude of external contacts that actors must simultaneously maintain.

\section{Boundaries of Irrelevance}

In sociological theory of course, the dominant organizing mode of modern (Western) societies is not segmentation but functional differentiation. As interpreteted in post-Parsonian neo-functionalism (Luhmann, 1984), functionally specialized societal subsystems - including politics, law, science or the economy - are construed as self-referential and 'autopoietic' systems of meaning, each with its own function-specific 'code' and 'medium' of communication. Communications that are not expressed in the specific code of a particular subsystem, and that are not supported by its appropriate medium, are simply meaningless and hence irrelevant within that subsystem. As a consequence, 'intersystemic discourse' is considered to be difficult if not downright impossible (Luhmann, 1986; Willke, 1989) - an interpretation that seems to find support in the apparent difficulties of political control of the economy (Luhmann, 1988), of the legal system (Teubner, 1989), or of the science system (Luhmann, 1990; Mayntz and Scharpf, 1990).

In the present context, however, it is important that functional differentiation may be even more effective than ingroup-outgroup differentiation in

28. Drawing upon Max Weber's studies in economic history, Siegwart Lindenberg (1988: 43) has recently argued that it is not only the 'opportunism with guile' expected from outsiders, but also the norms of 'strong solidarity' among insiders, that would be incompatible with the functioning of a modern, capitalist economy. The assumption is that groups united by their common distrust of outsiders will develop Gemeinschaft-like sharing norms (Tönnies, 1935) in their internal interactions that may work against capital accumulation and efficiency. 
protecting a privileged class of interactions against the backward induction of uncertainty. If communications pertaining to different systems of meaning are insulated from each other by boundaries of irrelevance, a vast range of existing outside contacts may simply, and safely, be ignored by the parties to a present interaction. Individual and corporate actors, ${ }^{29}$ in other words, may simultaneously participate in multiple communication systems that need not be separated by boundaries of suspicion and hostility in order to avoid interference.

The practical importance of such boundaries is dramatically brought home in accounts of the glaring inefficiencies of 'real-existing' socialist systems. There, functional differentiation was largely displaced by an extreme fusion of functions - law, public administration, business, science, the arts, etc. - under the postulated primacy of the political subsystem. Since the political implications of business decisions, scientific discoveries or artistic inventions could never be safely ignored, interactions must have become overcomplex and unpredictable - and actors did in fact revert to socially inefficient strategies of generalized distrust, restricting the possibility of trustful communication to highly personalized ingroups. In societies with fully developed functional differentiation, by contrast, political, economic, scientific or artistic games can be played side-by-side according to their own specific logics, and without interfering with each other even when there should be a wide overlap of players.

Yet the very efficiency of functional differentiation must create its own problems within this theoretical framework. Boundaries of irrelevance may segregate systems of communications, but they do not have the power to interrupt chains of real interdependence among functional subsystems. If these were systematically excluded from attention, differentiated subsystems would generate massive externalities for each other which could be as disastrous in their consequences as was the socialist attempt to subordinate all societal functions to the logic of the political system. These implications are acknowledged and even emphasized in neo-functionalist theory (Luhmann, 1986), but attempts to specify the conditions of 'intersystemic discourse' within the same theoretical framework have not yet succeeded (Willke, 1989). The theory, in other words, may explain boundaries between games, but it has not been able to conceptualize the possibility of predictable game-like interactions cutting across functional boundaries.

In the real world, of course, such interactions must occur continuously -

29. Yet one should not deny, as Luhmann does, that it is actors, individual and corporate, that act within differentiated communications systems. Since certain basic actor-interests will cut across multiple involvements, functional subsystems can never be watertight compartments (Pokol, 1990). Thus, conflict-of-interest rules may be needed to strengthen the boundary between business and politics, and ubiquitous instances of corruption and nepotism suggest that, even when so reinforced, functional differentiation is far from failure proof. 
between scientists and corporate managers in industrial research, between lawyers and politicians in the legislative process, between administrative agencies and business firms in environmental regulation, and across all other boundaries as well.

In our search for boundaries that might protect the integrity of 'constituent games' against cognitively unmanageable complexity and the backward induction of uncertainty, we have thus found two general mechanisms, ingroup-outgroup segmentation and functional differentiation. Taken by themselves, however, both would also raise near-insuperable barriers against trustworthy or meaningful communication across the boundary. That may often be true, but it cannot be generally true in modern societies. We thus need to extend our search further to mechanisms that are able to connect as well as to separate, and whose operation, compared to the universalism of segmental and functional differentiation, must be more specific and more contingent. Such possibilities will be explored in a subsequent paper that focuses on the potential contribution that concepts of hierarchical organization and of network-like interactions might make to the game-theoretic reconstruction of real-world interactions under the conditions of complex modern societies and polities.

\section{REFERENCES}

Akerlof, George A. (1970) 'The Market for "Lemons": Quality Uncertainty and the Market Mechanism', Quarterly Journal of Economics 90: 488-500.

Aldrich, Howard E. (1979) Organizations and Environments. Englewood Cliffs, NJ: Prentice-Hall.

Alt, James E. and Barry Eichengreen (1987) 'Overlapping and Simultaneous Games: Theory and Applications'. Paper prepared for the NBER Conference on 'The Political Economy of International Macroeconomic Policy Coordination'. Andover, MA, 6-7 November 1987.

Alt, James E., Robert D. Putnam and Kenneth A. Shepsle (1988) 'The Architecture of Linkage'. Paper prepared for the Workshop on 'Connected Games: Theory, Methodology, and Applications', Max-Planck-Institut für Gesellschaftsforschung, Cologne, 17-18 November 1988 .

Anderson, John H. (1982) 'Acquisition of Cognitive Skill', Psychological Review 89: 369-406.

Arrow, Kenneth J. (1951) Social Choice and Individual Values. New York: Wiley.

Banfield, Edward C. (1958) The Moral Basis of a Backward Society. New York: Free Press.

Brams, Steven J. (1977) 'Deception in $2 \times 2$ Games', Journal of Peace Science 2: 171-203.

Brams, Steven J. and Donald Wittman (1981) 'Nonmyopic Equilibria in $2 \times 2$ Games', Conflict Management and Peace Science 6: 39-62.

Brennan, Geoffrey and James M. Buchanan (1985) The Reason of Rules. Constitutional Political Economy. Cambridge: Cambridge University Press.

Buchanan, James M. (1954) ‘Social Choice, Democracy, and Free Markets', Journal of Political Economy 62: 114-23.

Buchanan, James M. and Gordon Tullock (1962) The Calculus of Consent. Ann Arbor: University of Michigan Press.

Coleman, James S. (1974) Power and the Structure of Society. New York: W. W. Norton.

Coleman, James S. (1981) The Asymmetric Society. Syracuse, NY: Syracuse University Press. 
Coleman, James S. (1986) 'Social Structure and the Emergence of Norms Among Rational Actors', in Andreas Diekmann and Peter Mitter (eds) Paradoxical Effects of Social Behavior: Essays in Honor of Anatol Rapoport, pp. 55-83. Heidelberg: Physica.

Coleman, James S. (1990) Foundations of Social Theory. Cambridge, MA: Harvard University Press.

Colman, Andrew (1982) Game Theory and Experimental Games: The Study of Strategic Interaction. Oxford: Pergamon.

Denzau, Arthur, William Riker and Kenneth Shepsle (1985) 'Farquharson and Fenno: Sophisticated Voting and the Home Style', American Political Science Review 79: 1117-37.

Deutschmann, Christoph (1989) 'Der “Clan” als Unternehmensmodell der Zukunft?' Leviathan 17: 85-107.

Eden, Colin, Sue Jones, David Sims and Tim Smithin (1981) 'The Intersubjectivity of Issues and Issues of Intersubjectivity', Journal of Management Studies 18: 37-47.

Elster, Jon (1979) Ulysses and the Sirens: Studies in Rationality and Irrationality. Cambridge: Cambridge University Press.

Elster, Jon (1983) Explaining Technical Change: A Case Study in the Philosophy of Science. Cambridge: Cambridge University Press.

Fang, Liping, Keith W. Hipel and D. Marc Kilgour (1989) 'Conflict Models in Graph Form: Solution Concepts and their Interrelationships', European Journal of Operational Research 41: 86-100.

Farquharson, Robin (1969) Theory of Voting. Oxford: Basil Blackwell.

Feld, Scott L. and Bernard Grofman (1990) 'Collectivities as Actors: Consistency of Collective Choices', Rationality and Society 2: 429-48.

Fischer, Klaus (1989) 'Die kognitive Konstitution sozialer Strukturen', Zeitschrift für Soziologie 18: 16-34.

Fishburn, Peter C. and D. Marc Kilgour (1990) 'Binary $2 \times 2$ Games', Theory and Decision 29: 165-82.

Fraser, Niall M. and Keith W. Hipel (1984) Conflict Analysis. Models and Resolutions. New York: North Holland.

Fraser, Niall M. and D. Marc Kilgour (1986) 'Non-Strict Ordinal $2 \times 2$ Games: A Comprehensive Computer-Assisted Analysis of the 726 Possibilities', Theory and Decision 20: 99-121.

Frey, Bruno S. (1990) 'From Paradoxes to Social Rules, or: How Economics Repeats Itself', Constitutional Political Economy 1: 27-34.

Granovetter, Mark (1978) 'Threshold Models of Collective Behavior', American Journal of Sociology 83: 1420-43.

Granovetter, Mark (1985) 'Economic Action and Social Structure: The Problem of Embeddedness', American Journal of Sociology 91: 481-510.

Granovetter, Mark and Roland Soong (1983) 'Threshold Models of Diffusion and Collective Behavior', Journal of Mathematical Sociology 9: 165-79.

Greif, Avner, Paul Milgrom and Barry Weingast (1990) 'The Merchant Gild as a Nexus of Contracts'. Stanford, CA: Hoover Institution Working Paper in Economics E-90-23.

Haffner, Sebastian (1987) 'Die Pariser Kommune', Sebastian Haffner, Im Schatten der Geschichte. Historisch-politische Variationen aus zwanzig Jahren, pp. 61-103. Munich: Deutscher Taschenbuch Verlag.

Hardin, Garrett and John Baden, eds (1977) Managing the Commons. San Francisco: Freeman.

Harsanyi, John C. (1977) Rational Behavior and Bargaining Equilibrium in Games and Social Situations. Cambridge: Cambridge University Press.

Heiner, Ronald A. (1983) 'The Origin of Predictable Behavior', American Economic Review 73: 560-595.

Holler, Manfred J. and Voggo Host (1990) 'Maximin vs. Nash Equilibrium: Theoretical Results and Empirical Evidence', in Richard E. Quandt and Dusan Triska (eds) Optimal Decisions 
in Markets and Planned Economies, pp. 245-55. Boulder, CO: Westview Press.

Howard, Nigel (1971) Paradoxes of Rationality. Cambridge, MA: MIT Press.

Johnstone, A. H. and H. El-Bana (1989) 'Understanding Learning Difficulties - A Predictive Research Model', Studies in Higher Education 14: 159-68.

Kahan, James P. and Amnon Rapoport (1984) Theories of Coalition Formation. Hillsdale, NJ: Erlbaum.

Kelley, Harold H. and John W. Thibaut (1978) Interpersonal Relations: A Theory of Interdependence. New York: Wiley.

Kilgour, D. Marc and Niall M. Fraser (1988) 'A Taxonomy of all Ordinal $2 \times 2$ Games', Theory and Decision 24: 99-117.

Kliemt, Hartmut and B. Schauenberg (1984) 'Coalitions and Hierarchies: Some Observations on the Fundamentals of Human Cooperation', Manfred J. Holler (ed.) Coalitions and Collective Action, pp. 9-32. Wuerzburg: Physica.

Kreps, David M. and Robert Wilson (1982) 'Reputation and Imperfect Information', Journal of Economic Theory 27: 253-79.

Laver, Michael and Kenneth A. Shepsle (1990) 'Government Coalitions and Intraparty Politics', British Journal of Political Science 20: 489-507.

Liebrand, Wim B.G. and Godfried J. van Rung (1985) 'The Effects of Social Motives on Behavior in Social Dilemmas in Two Cultures', Journal of Experimental Social Psychology 21: 86-102.

Lindenberg, Siegwart (1988) 'Contractual Relations and Weak Solidarity: The Behavioral Basis of Restraints on Gain-maximization', Journal of Institutional and Theoretical Economics 144: 39-58.

Luhmann, Niklas (1984) Soziale Systeme. Grundriß einer allgemeinen Theorie. Frankfurt: Suhrkamp.

Luhmann, Niklas (1986) Ökologische Kommunikation. Opladen: Westdeutscher Verlag.

Luhmann, Niklas (1988) Die Wirtschaft der Gesellschaft. Frankfurt: Suhrkamp.

Luhmann, Niklas (1988a) 'Familiarity, Confidence, Trust: Problems and Alternatives', Diego Gambetta (ed.) Trust: Making and Breaking Cooperative Relations, pp. 94-107. Oxford: Basil Blackwell.

Luhmann, Niklas (1990) Die Wissenschaft der Gesellschaft. Frankfurt: Suhrkamp.

Macy, Michael W. (1989) 'Walking Out of Social Traps', Rationality and Society 1: 197-219.

Mayntz, Renate and Birgitta Nedelmann (1987) 'Eigendynamische soziale Prozesse: Anmerkungen zu einem analytischen Paradigma', Kölner Zeitschrift für Soziologie und Sozialpsychologie 39: 648-68.

Mayntz, Renate and Friedhelm Neidhardt (1989) 'Parlamentskultur: Handlungsorientierungen von Bundestagsabgeordneten - eine empirisch-explorative Studie', Zeitschrift für Parlamentsfragen 20: 370-87.

Mayntz, Renate and Fritz W. Scharpf (1990) 'Guidance and Control of Research Systems', in Helmar Krupp (ed.) Technikpolitik angesichts der Umweltkatastrophe, pp.61-83. Heidelberg: Physica.

McClintock, Charles G. and Wim B.G. Liebrand (1988) 'Role of Interdependence Structure, Individual Value Orientation, and Another's Strategy in Social Decision Making: A Transformational Analysis', Journal of Personality and Social Psychology 55: 396-409.

McKelvey, Richard D. and Richard G. Niemi (1978) 'A Multistage Game Representation of Sophisticated Voting for Binary Procedures', Journal of Economic Theory 18: 1-22.

Milgrom, Paul R., Douglass C. North and Barry R. Weingast (1988) 'Third Party Enforcement of Norms and Contracts: A Theoretical-Historical Analysis'. Paper prepared for the "Workshop on Connected Games", Max-Planck-Institut für Gesellschaftsforschung, Cologne, 17-18 November 1988.

Miller, G.A. (1956) 'The Magical Number Seven, Plus or Minus Two: Some Limits on Our Capacity for Processing Information', Psychological Review 63: 81-97. 
Miller, Gary J. and Terry M. Moe (1986) 'The Positive Theory of Hierarchies', Herbert F. Weisberg (ed.) Political Science: The Science of Politics, pp. 167-98. New York: Agathon Press.

Nelson, Richard R. and Sidney G. Winter (1982) An Evolutionary Theory of Economic Change. Cambridge, MA: Belknap Press.

Nolte, Detlev (1988) 'Ist die Koalitionstheorie am Ende? Eine Bilanz nach 25 Jahren Koalitionsforschung', Politische Vierteljahresschrift 29: 230-51.

Offe, Claus (1988) 'Reflections on the Institutional Self-Transformation of Movement Politics: A Tentative Stage Model', MS, Fakultät für Soziologie, University of Bielefeld.

Offe, Claus (1989) 'Fessel und Bremse. Moralische und institutionelle Aspekte "intelligenter Selbstbeschränkung"', Axel Honneth, Thomas McCarthy, Claus Offe and Albrecht Wellemer (eds) Zwischenbetrachtung. Im Prozess der Aufklärung: Jürgen Habermas zum 60. Geburtstag, pp. 739-74. Frankfurt: Suhrkamp.

Ordeshook, Peter C. (1986) Game Theory and Political Theory: An Introduction. Cambridge: Cambridge University Press.

Ostrom, Elinor (1986) 'An Agenda for the Study of Institutions, Public Choice 48: 3-25.

Ostrom, Elinor (1989) 'Microconstitutional Change in Multiconstitutional Political Systems', Rationality and Society 1: 11-50.

Ostrom, Elinor (1990) Governing the Commons: The Evolution of Constitutions for Collective Action. Cambridge: Cambridge University Press.

Ouchi, William G. (1984) The M-Form Society: How American Teamwork Can Recapture the Competitive Edge. Reading, MA: Addison-Wesley.

Pagden, Anthony (1988) 'The Destruction of Trust and its Economic Consequences in the Case of Eighteenth-century Naples', in Diego Gambetta (ed.) Trust: Making and Breaking Cooperative Relations, pp. 127-41. Oxford: Basil Blackwell.

Pokol, Béla (1990) 'Professionelle Institutionensysteme oder Teilsysteme der Gesellschaft? Reformulierungsvorschläge zu Niklas Luhmanns Systemtypologie', Zeitschrift für Soziologie 19: 329-44.

Putnam, Robert D. (1988) 'Diplomacy and Domestic Politics: The Logic of Two-level Games', International Organization 42: 429-60.

Putnam, Robert D. and Nicholas Bayne (1984) Hanging Together: The Seven-Power Summits. Cambridge, MA: Harvard University Press.

Rapoport, Anatol (1970) N-Person Game Theory: Concepts and Applications. Ann Arbor: University of Michigan Press.

Rapoport, Anatol and Melvin G. Guyer (1966) 'A Taxonomy of $2 \times 2$ Games', General Systems 11: 203-14.

Rasmussen, Eric (1989) Games and Information: An Introduction to Game Theory. Oxford: Basil Blackwell.

Raub, Werner and Gideon Keren (1990) 'Hostages as a Commitment Device: A Game-Theoretic Model and an Empirical Test of Some Scenarios'. MS. Faculty of Social Sciences, Utrecht University.

Riker, William H. and Peter C. Ordeshook (1973) An Introduction to Positive Political Theory. Englewood Cliffs, NJ: Prentice-Hall.

Scharpf, Fritz W. (1987) 'A Game-theoretical Interpretation of Inflation and Unemployment in Western Europe', Journal of Public Policy 7: 227-57.

Scharpf, Fritz W. (1988) 'The Joint Decision Trap: Lessons from German Federalism and European Integration', Public Administration 66: 239-87.

Scharpf, Fritz W. (1989) 'Decision Rules, Decision Styles and Policy Choices', Journal of Theoretical Politics 1: 149-76.

Scharpf, Fritz W. (1990) 'Games Real Actors Could Play: The Problem of Mutual Predictability', Rationality and Society 2: 471-94. 
Schelling, Thomas C. (1960) The Strategy of Conflict. Cambridge, MA: Harvard University Press.

Schelling, Thomas C. (1984) Choice and Consequence. Cambridge, MA: Harvard University Press.

Schmitt, Carl (1932) Der Begriff des Politischen: Text von 1932 mit einem Vorwort und drei Corollarien. Berlin: Duncker \& Humblot, 1963.

Schotter, Andrew (1981) The Economic Theory of Social Institutions. Cambridge: Cambridge University Press.

Selten, Reinhard and Klaus G. Schuster (1970) 'Psychologische Faktoren bei Koalitionsverhandlungen', in H. Sauermann (ed.) Beiträge zur experimentellen Wirtschaftsforschung II, pp. 99-135. Tübingen: Mohr.

Sen, Amartya (1970) 'The Impossibility of a Paretian Liberal', Journal of Political Economy 78: 152-7.

Shepsle, Kenneth A. (1985) 'Cooperation and Institutional Arrangements'. Paper prepared for the Harvard Conference on International Regimes and Cooperation, 13-15 February 1986.

Snyder, Glenn H. and Paul Diesing (1977) Conflict among Nations: Bargaining, Decision Making, and System Structure in International Crises. Princeton: Princeton University Press.

Stackelberg, Heinrich von (1934) Marktform und Gleichgewicht. Berlin: Springer.

Teubner, Gunther (1989) Recht als autopoietisches System. Frankfurt: Suhrkamp.

Thompson, James D. (1967) Organizations in Action: Social Science Bases of Administrative Theory. New York: McGraw-Hill.

Tönnies, Ferdinand $(1935 / 1979)$ Gemeinschaft und Gesellschaft: Grundbegriffe der reinen Soziologie. Reprint of the 8th edition dated 1935. Darmstadt: Wissenschaftliche Buchgesellschaft.

Tsebelis, George (1988) 'Nested Games: The Cohesion of French Electoral Coalitions', British Journal of Political Science 18: 145-70.

Tsebelis, George (1989) 'Thucydides on Nash vs. Stackelberg: The Importance of Sequence of Moves in Games'. MS. Department of Political Science, UCLA.

Tsebelis, George (1990) Nested Games: Rational Choice in Comparative Politics. Berkeley: University of California Press.

Turkle, Sherry (1988) 'Artificial Intelligence and Psychoanalysis: A New Alliance', Daedalus 117: 241-68.

Turner, Marilyn and Randall W. Engle (1989) 'Is Working Memory Capacity Task Dependent?' Journal of Memory and Language 28: 127-54.

Von Neumann, John and Oskar Morgenstern (1944) Theory of Games and Economic Behavior, 3rd edn 1953. Princeton: Princeton University Press.

Weissing, Franz and Elinor Ostrom (1990) 'Irrigation Institutions and the Games Irrigators Play: Rule Enforcement without Guards'. MS. Workshop in Political Theory and Policy Analysis, Indiana University.

Wiesenthal, Helmut (1990) Unsicherheit und Multiple-Self-Identität. Eine Spekulation über die Voraussetzungen strategischen Handelns. Köln: MPIFG Discussion Paper 90/2.

Williamson, Oliver E. (1975) Markets and Hierarchies: Analysis and Antitrust Implications. New York: Free Press.

Williamson, Oliver E. (1985) The Economic Institutions of Capitalism: Firms, Markets, Relational Contracting. New York: Free Press.

Willke, Helmut (1989) Systemtheorie entwickelter Gesellschaften. Dynamik und Riskanz moderner gesellschaftlicher Selbstorganisation. Weinheim: Juventa.

Zagare, Frank C. (1984) 'Limited-Move Equilibria in $2 \times 2$ Games', Theory and Decision 16: 1-19. 
FRITZ W. SCHARPF, born 1935 in Germany, studied Law and Political Science at the universities of Tübingen, Freiburg and Yale. He was Assistant Professor of Law at Yale 1964-6, and Professor of Political Science at Konstanz 1968-73. From 1973 to 1984 he was Director of the International Institute of Management, Wissenschaftszentrum, Berlin, and as from 1986 he is the Director of the Max-Planck-Institut für Gesellschaftsforschung, Köln. ADDRESS: Lothringer Str. 78, D-5000, Köln, Germany.

Paper submitted 10 June 1990; accepted for publication 4 August 1990. 